\title{
PREDISTENTION OF THE EPIDURAL SPACE WITH NORMAL SALINE BEFORE CATHETER INSERTION REDUCES THE INCIDENCE OF INADVERTENT INTRAVASCULAR EPIDURAL CATHETER PLACEMENT
}

\author{
Sanchita Sarma Borkataki ${ }^{1}$ Deba Gopal Pathak ${ }^{2}$
}

${ }_{1}^{1}$ Assistant Professor, Department of Anaesthesiology and Critical Care, Gauhati Medical College and Hospital.

2 Professor and HOD, Department of Anaesthesiology and Critical Care, Silchar Medical College and Hospital.

ABSTRACT
BACKGROUND
Accidental cannulation of an epidural vein is a common complication associated with continuous epidural anaesthesia or analgesia.
Based on available literature, we studied and tested the hypothesis that predistention of the epidural space with saline before
epidural catheterisation would ease catheter insertion and decrease the incidence of this complication.

\section{MATERIALS AND METHODS}

Two hundred women for elective caesarean section were randomly assigned to receive an epidural with loss of resistance technique with $2 \mathrm{~mL}$ (non-distention group) or $5 \mathrm{~mL}$ normal saline (distention group). In the distention group, the syringe plunger was held close for 20 seconds before epidural catheter insertion. Then in both groups, a test dose of $3 \mathrm{~mL}$ of $2 \%$ lidocaine with adrenaline was injected through the epidural catheter.

\section{RESULTS}

There were fewer accidental intravascular catheter placements ( $2 \%$ vs $15 \%$, P value 0.001$)$ in the distention group compared to the non-distention group.

\section{CONCLUSION}

Distention of the epidural space with $5 \mathrm{~mL}$ normal saline before epidural catheter insertion decreased the incidence of accidental venous cannulation (Anesth Analg 2007; 105: 460-4) and can make unintentional intravascular catheter placement an avoidable complication.

\section{KEYWORDS}

Epidural Space, Normal Saline, Predistention, Intravascular.

HOW TO CITE THIS ARTICLE: Borkataki SS, Pathak DG. Predistention of the epidural space with normal saline before catheter insertion reduces the incidence of inadvertent intravascular epidural catheter placement. J. Evolution Med. Dent. Sci. 2018;7(03): 306-309, DOI: $10.14260 /$ jemds/2018/68

\section{BACKGROUND}

Identification of the epidural space by loss of resistance (LOR) technique with normal saline (NS) or lidocaine is superior to the use of air.(1-6) But once the space is identified, some clinicians inject additional NS into it before catheter insertion,(7-9) whereas others do not.(4,5) Accidental cannulation of an epidural vein is a common complication associated with insertion of epidural catheter for either continuous epidural anaesthesia or analgesia. The epidural veins become particularly engorged in pregnancy due to the intermittent obstruction of the inferior vena cava by the enlarging uterus, thus encouraging venous drainage through alternative pathways like vertebral and azygous venous system. The epidural veins are part of the internal vertebral venous plexus and these veins become particularly engorged during pregnancy.

The aim of our study is that injecting a low volume of normal saline (NS) before catheter insertion and holding the

'Financial or Other Competing Interest': None.

Submission 18-11-2017, Peer Review 27-12-2017,

Acceptance 03-01-2018, Published 13-01-2018.

Corresponding Author:

Dr. Sanchita Sarma Borkataki,

Assistant Professor

Department of Anaesthesiology and Critical Care,

Gauhati Medical College and Hospital,

Guwahati, Assam

E-mail: sbsarma1@gmail.com

DOI: $10.14260 /$ jemds $/ 2018 / 68$

\section{(c) (1) $(9)$}

syringe plunger closed would distend the epidural space and reduce the propensity for accidental venous cannulation.

\section{MATERIALS AND METHODS}

After approval of the Institutional Ethical Committee and written informed consent, 208 ASA class I-II nulliparous women with singleton pregnancy at term, undergoing elective caesarean section were enrolled for continuous epidural anaesthesia. According to the study protocol, 200 cases which met all the inclusion criteria were selected for the study and divided into two groups: 100 patients in each-

1. Non-distention group (Group ND) -2 mL NS.

2. Distention group (Group D) $-5 \mathrm{~mL} \mathrm{NS}(2 \mathrm{~mL}+3 \mathrm{~mL})$.

We excluded patients with preeclampsia; morbid obesity; coagulopathy; history of drug or alcohol abuse; heavy smoking; neurological complaint or abnormal hepatic, renal or haematological test results.

\section{Study Design}

Prospective randomised control parallel arm study.

Sample size was calculated by considering the incidence of accidental venous cannulation of $30 \%$ in previous study; to detect the difference of $15 \%$ with the power of $80 \%$ at the significance level of 0.9 . It was found that 93 patients were required in each group. Considering possible dropout, we decided to take a sample size of 100 in each group. 
Standardised management was used in all patients. Patients were randomly allocated to receive epidural anaesthesia with or without distention of the epidural space before placement of the epidural catheter. Randomisation was simple and was based on computer-generated codes that were maintained in sequentially numbered opaque envelopes until just before use. The randomisation envelopes were opened and the designated treatment was started. Patients were blinded to treatment, as was the anaesthesiologist who recorded or evaluated outcomes. Anaesthesiologists with at least 4-year experience in obstetric anaesthesia and familiar with the LOR technique were responsible for initiating epidural.

All patients were visited on the day prior to surgery for pre-anaesthetic assessment and were explained in detail about the procedure of epidural anaesthesia with catheter in an understandable manner. Demographic data, physical examination findings and laboratory investigations were recorded systemically. Fasting was advised as per ASA guideline.

On the day of operation, patients were again examined and shifted to the operation theatre. Intravenous line was established with 18-G IV cannula and all monitors like noninvasive blood pressure, electrocardiography and pulse oximeter were attached to each patient. Acid aspiration prophylaxis was given in all the patients.

In both the groups, patients were preloaded with 10 $\mathrm{mL} / \mathrm{kg}$ RL. Taking proper aseptic and antiseptic measures, epidural was given with an 18-G Tuohy epidural needle (B. Braun), in sitting position; inserted at the Lumbar (L) 3 - 4 or L2 - 3 intervertebral space by a midline approach with the needle orifice directed cephalad, using loss of resistance (LOR) technique with NS, $2 \mathrm{~mL}$ (non-distention) or $5 \mathrm{~mL}$ (distention), to identify the epidural space before insertion of the epidural catheter. After identification of the epidural space, and in the absence of blood or cerebrospinal fluid at the needle's hub, in the ND group where $2 \mathrm{~mL}$ NS was used, a 20-G multi-orifice epidural catheter (B. Braun) was threaded $3-4 \mathrm{~cm}$ into the epidural space through the needle. In the D group $5 \mathrm{~mL}$ NS was injected into the epidural space, while the syringe plunger was held closed for 20 secs. (The time period was found appropriate to avoid backflow). Then the catheter was inserted 3 to $4 \mathrm{~cm}$ as in ND group. Catheter was fixed properly in both the groups. After confirming that no blood or cerebrospinal fluid returned through the catheter upon aspiration or by free flow to gravity, proper placement of catheter was confirmed by aspiration and giving test dose with $3 \mathrm{~mL}$ of $2 \%$ Lidocaine with adrenaline in both the groups.

\section{Each Patient of both the Groups was observed for-}

1. The development of sensory blockade in the lower dermatomes,

2. For the inability to move the toes as evidence of unintentional subarachnoid injection. Patients were simultaneously assessed for,

3. Symptoms of central nervous system irritability produced by subtoxic doses of lidocaine, and
4. Any significant changes in heart rate produced by adrenaline as an indication of unintentional intravascular injection.

Patients were placed in the left lateral position and 5 mins later if there were no signs of subarachnoid or intravascular injection, $16 \mathrm{~mL}$ Bupivacaine $0.5 \%$ and $0.15 \mathrm{mg}$ Buprenorphine was injected epidurally. After establishment of adequate blockade, surgery was started and completed successfully.

Maternal monitoring consisted of non-invasive arterial blood pressure, heart rate and $\mathrm{SPO}_{2}$ measurements. Routine demographic characteristics, ASA grading and gestational age were assessed before beginning the epidural procedure. The anaesthesiologist who performed the epidural procedure recorded the occurrence of inadvertent intravascular or subarachnoid insertion of the catheter as indicated by aspiration of blood or free flow of clear fluid.

\section{Statistical Analysis}

Inadvertent intravascular insertion of the epidural catheter was defined as the primary outcome.

Data were analysed by specific statistical methods applicable to the various sets of data. Test employed was Pearson Chi-square test, which was performed on SPSS 21.0 version software. Microsoft Excel 2007 has been used to generate graphs and tables. Independent ' $\mathrm{t}$ ' test was used for comparing the means. In case of gestational age which is a categorical variable, ' $\mathrm{t}$ ' test is not applied-

- P value: $>0.05=$ Not Significant.

- $\quad<0.05=$ Significant.

- $\quad<0.001=$ Highly Significant

\section{RESULTS}

The study was completed by 200 of 208 ASA class I - II nulliparous women with singleton pregnancy at term, undergoing elective caesarean section with continuous epidural anaesthesia. The remaining eight patients were excluded from the study, because they developed preeclampsia. Among the 200 patients who completed the study, 100 were allocated to the non-distention group and 100 to the distention group. There were no epidural failures. The vitals were stable. Patient's demographic characteristics (age, weight, height) and gestational age were similar in the two groups (Table 1, Figure 1).

There were fewer accidental intravascular catheter insertions ( $2 \%$ vs $15 \%$, P value 0.001 ) in the distention group (Table 2, Figure 2), which was significantly less. There were no intrathecal catheter placements.

\begin{tabular}{|c|c|c|c|c|}
\hline & Group D & Group ND & $\begin{array}{c}\text { T test } \\
\text { value }\end{array}$ & P value \\
\hline Age & $27.39 \pm 4.020$ & $27.23 \pm 3.643$ & 0.295 & 0.768 \\
\hline Weight & $58.95 \pm 3.214$ & $59.51 \pm 3.221$ & -1.231 & 0.220 \\
\hline Height & $153.69 \pm 5.049$ & $153.99 \pm 5.139$ & -0.416 & 0.678 \\
\hline \multicolumn{4}{|c|}{ Table 1. Demographic Data } \\
\hline
\end{tabular}




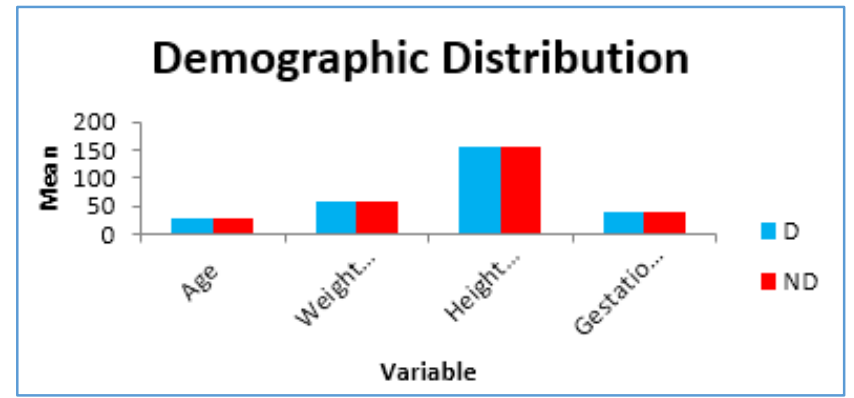

\begin{tabular}{|c|c|c|c|c|}
\hline \multicolumn{5}{|c|}{ Figure 1. Demographic Data } \\
\hline $\begin{array}{c}D \\
(N=100)\end{array}$ & $\begin{array}{c}\text { ND } \\
(\mathrm{N}=100)\end{array}$ & $\begin{array}{l}\text { Pearson Chi- } \\
\text { Square Value }\end{array}$ & P Value & Remark \\
\hline 2 & 15 & 10.865 & .001 & $\begin{array}{c}\text { Highly } \\
\text { Significant }\end{array}$ \\
\hline
\end{tabular}

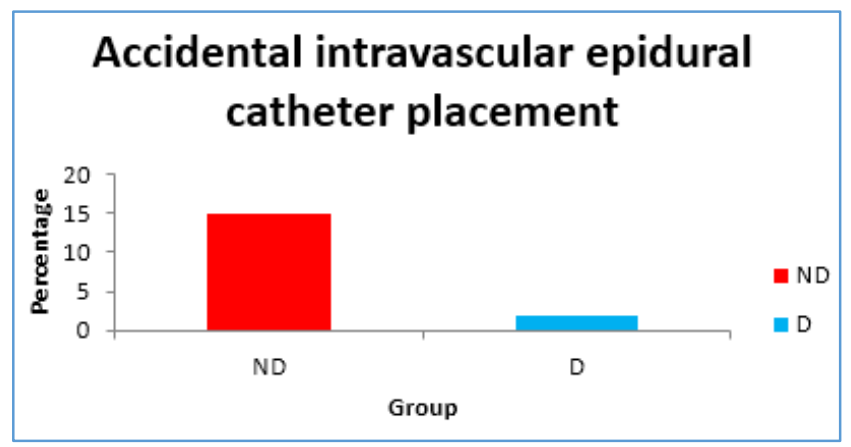

Figure 2. Accidental Intravascular Epidural Catheter Placement

\section{DISCUSSION}

We demonstrated that distention of the epidural space with 5 $\mathrm{mL}$ versus $2 \mathrm{~mL}$ NS before epidural catheter insertion decreased the incidence of accidental intravascular placement. The idea of our study was that once the epidural space is identified, further distention of the epidural space with an incompressible fluid like Normal Saline (NS) would provide lubrication and push blood vessels and other components away from the catheter. We hypothesised that this distention would in turn facilitate catheter insertion and reduce the incidence of accidental intravascular catheterisations. Our results were therefore consistent with this theory.

The amount of NS used in previous studies of LOR varied. Beilin et al(5) used $2 \mathrm{~mL}$, while Valentine et al(4) used $4 \mathrm{~mL}$ NS; however, both groups compared the speed of onset of analgesia with that achieved by using the same volume of air for LOR. Others injected additional volumes of NS into the epidural space, before or after catheter insertion. Sarna et al(10) for example injected $10 \mathrm{~mL}$ of NS or air during or after the search for LOR and found no difference in analgesia and complication rate. Iwama(11) compared the quality of analgesia and incidence of complications using 2 or $10 \mathrm{~mL}$ NS for LOR. Using NS to distend the epidural space is but one method of reducing accidental venous puncture. For example, Landa et al found that puncture risk can be reduced by cephalad needle angulation(12) by using softer epidural catheter tips or by having epidural injection performed by an experienced anaesthesiologist as found by Banwell et al(13) and Bahar et al $(14,15)$ were able to decrease the rate of this complication from $11 \%$ to $2 \%$ in both non-obese and obese parturients by performing the epidural with the patient in the head-down lateral recumbent position rather than the sitting position. Gadalla et al(7) used an unknown volume of air with LOR for combined spinal-epidural labour analgesia. While injecting $10 \mathrm{~mL}$ NS before epidural catheter placement, they were able to reduce the incidence of accidental venous cannulation from $20 \%$ to $2 \%$ when compared to the non-NS injection patient group. Mannion et al( ${ }^{(8)}$ assessed the effect of patient's position, diameter of epidural catheter and the injection of $10 \mathrm{~mL}$ NS before epidural catheterisation on the incidence of accidental epidural venous cannulation. The epidural space was identified with LOR with air. The injection of $10 \mathrm{~mL}$ of NS through an 18-G epidural needle before epidural catheterisation with the patients in sitting position decreased the incidence of venous cannulation from $16 \%$ to $0 \%$. Patient position had no significant effect on this complication. In another study Rolbin SH et al(9) derived that the injection of smaller volumes of NS or lidocaine $(3 \mathrm{~mL})$ after identification of the epidural space with LOR with $2 \mathrm{~mL}$ of air did not reduce the incidence of accidental epidural venous cannulation. The differences in the results may stem from the different techniques used, patient position, the volume of fluid injected or catheter type inserted. Many studies found no differences in the incidence of intravascular cannulation when LOR to air was compared with LOR to NS.

Using our technique, we achieved fewer accidental intravascular cannulations with a smaller volume of NS, but with the syringe plunger held closed for 20 s before catheter insertion to maintain the NS within the epidural space. Similar to that found by Evron et al(1) and Beilin et al,(5) we found that $2 \mathrm{~mL}$ of NS was sufficient for detecting the epidural space with LOR. This was also the minimal volume required in the control group without distending the epidural space. Presence of blood/ free flow of blood at the needle hub prior to catheter insertion was regarded as evidence of blood vessel puncture. Free flow and aspiration of blood and CSF from catheter was noticed before giving drug through catheter.

\section{CONCLUSION}

Unintentional intravascular catheter placement is an unwanted, but common complication in our day-to-day epidural anaesthesia or analgesia procedures. The simple technique of predistention of epidural space with $5 \mathrm{~mL}$ NS before placement of epidural catheter can make unintentional intravascular catheter placement an avoidable complication.

\section{REFERENCES}

[1] Evron S, Sessler D, Sadan 0, et al. Identification of the epidural pace: loss of resistance with air, lidocaine or the combination of air and lidocaine. Anesth Analg 2004;99(1):245-50.

[2] Scott DB. Identification of the epidural space: loss of resistanceto air or saline? Reg Anesth 1997;22(1):1-2.

[3] Russell R. Loss of resistance to saline is better than air for obstetric epidurals. Int J Obstet Anesth 2001;10(4): 302-4. 


\section{Jemds.com}

[4] Valentine SJ, Jarvis AP, Shutt LE. Comparative study of the effects of air or saline to identify the extradural space. Br J Anaesth 1991;66(2):224-7.

[5] Beilin Y, Arnold I, Telfeyan C, et al. Quality of analgesia when air versus saline is used for identification of the epidural space in the parturient. Reg Anesth \& Pain Med 2000;25(6):596-9.

[6] Shenouda PE, Cunningham BJ. Assessing the superiority of saline versus air for use in the epidural loss of resistance technique: a literature review. Reg Anesth Pain Med 2003;28(1):48-53.

[7] Gadalla F, Lee $\mathrm{SH}$, Choi $\mathrm{KC}$, et al. Injecting saline through the epidural needle decreases the iv epidural catheter placement rate during combined spinalepidural labour analgesia. Can J Anaesth 2003;50(4):382-5.

[8] Mannion D, Walker R, Clayton K. Extradural vein puncture--an avoidable complication. Anaesthesia 1991;46(7):585-7.

[9] Rolbin SH, Halpern SH, Braude BM, et al. Fluid through the epidural needle does not reduce complications of epidural catheter insertion. Can J Anaesth 1990;37(3):337-40.

\section{Original Research Article}

[10] Sarna MC, Smith I, James JM. Paraesthesia with lumbar epidural catheters. A comparison of air and saline in a loss-of-resistance technique. Anaesthesia 1990;45(12):1077-9.

[11] Iwama H. Injection volume of saline with loss of resistance method may affect the spread of epidural anesthesia. Anesthesiology 1997;86(2):507-8.

[12] Landa SE, Pai K, Winkoff SP. The insertion angle of epidural needle affect the success of the block (abstract). Anesthesiology 2003;98:A113.

[13] Banwell BR, Morley-Forster P, Krause R. Decreased incidence of complications in parturients with the arrow (Flex Tip Plus)epidural catheter. Can J Anaesth 1998;45(4):370-2.

[14] Bahar M, Chanimov M, Cohen ML, et al. Lateral recumbent head-down posture for epidural catheter insertion reduces intravascular injection. Can J Anaesth 2001;48(1):48-53.

[15] Bahar M, Chanimov M, Cohen ML, et al. The lateral recumbent head-down position decreases the incidence of epidural venous puncture during catheter insertion in obese parturients. Can J Anaesth 2004;51(6):577-80. 